\title{
The structure of avian eye lens $\delta$-crystallin reveals a new fold for a superfamily of oligomeric enzymes
}
A. Simpson, O. Bateman, H. Driessen, P. Lindley, D. Moss, S. Mylvaganam, E.
Narebor and C. Slingsby

Nature structural Biology 1, 724-734.

Table 1 was unfortunately omitted.

\begin{tabular}{|c|c|c|c|c|c|c|c|c|}
\hline \multicolumn{9}{|c|}{ Table 1 Phasing statistics } \\
\hline Data set & Resolution & Completeness & Multiplicity & $R_{\text {sym }}$ & $R_{\mathrm{iso}}$ & $\begin{array}{l}\text { Mean phasing } \\
\text { power, acentric }\end{array}$ & $\begin{array}{l}\text { Mean phasing } \\
\text { power, centric }\end{array}$ & $R_{\text {cullis }}$ \\
\hline native & $\begin{array}{l}3.5 \AA \\
2.5 \AA\end{array}$ & $\begin{array}{l}98.0 \% \\
95.7 \%\end{array}$ & $\begin{array}{l}2.5 \\
304\end{array}$ & $\begin{array}{l}5.5 \% \\
5.2 \%\end{array}$ & & & & \\
\hline $\mathrm{dmm}$ & $5.0 \AA$ & $97.5 \%$ & 3.0 & $3.9 \%$ & $17.3 \%$ & 2.5 & 1.4 & 0.76 \\
\hline dae & $5.5 \AA$ & $93.2 \%$ & 3.5 & $12.8 \%$ & $14.8 \%$ & 0.8 & 0.6 & 0.93 \\
\hline dam & $5.5 \AA$ & $85.1 \%$ & 3.3 & $7.7 \%$ & $36.9 \%$ & 0.7 & 0.4 & 0.95 \\
\hline $\mathrm{tml}$ & $5.0 \AA$ & $83.5 \%$ & 2.8 & $9.2 \%$ & $27.7 \%$ & 0.7 & 0.5 & 0.87 \\
\hline $\mathrm{dmm} 2$ & $3.5 \AA$ & $80.6 \%$ & 2.5 & $11.9 \%$ & $19.8 \%$ & 1.4 & 1.2 & 0.82 \\
\hline
\end{tabular}

$\mathrm{dmm}$ : dimethyl mercury (collected using rotating anode).

dae: cis-diamine-dichloro Pt (II)

dam: dichloro (ethylene diamine) Pt (II)

tm1: trimethyl lead chloride

$\mathrm{dmm} 2$ : dimethyl mercury (collected at the SRS).

Multiplicity is the mean number of observations per reflection.

$R_{\text {sym }}=\Sigma_{i}\left|I_{-} I_{m}\right| / \Sigma_{i} l_{i} \times 100$, where the sum is taken over the subset of reflections with multiple observations and $I m$ is the mean value of the ith intensity.

$R_{\text {isol }}=\Sigma\left|I_{\mathrm{ph}}-l_{\mathrm{p}}\right| / \Sigma I_{\mathrm{p}} \times 100$, where $I_{\mathrm{pH}}$ and $I_{\mathrm{p}}$ are the heavy atom and native intensities.

$R_{\text {cullis }}=$ (lack of closure) / (isomorphous difference)

Phasing power $=\left|\boldsymbol{F}_{\mathrm{H}}\right| /$ (lack of closure), where (isomorphous difference) $=\left|\boldsymbol{F}_{\mathrm{PH}}-\boldsymbol{F}_{\mathrm{P}}\right|_{\text {, }}$ (lack of closure) $=\left|\boldsymbol{F}_{\mathrm{PH}} \mathrm{l}_{\text {obs }}-\boldsymbol{F}_{\mathrm{PH}}\right|_{\text {obs }}$ is the observed derivative structure factor amplitude and $\boldsymbol{F}_{\mathrm{p}}+\boldsymbol{F}_{\mathrm{H}}$ is the vector sum of the calculated heavy atom and protein structure factors. 